\title{
A monumentalidade arquitetônica dentro do planejamento estratégico de cidades: a arquitetura rentista e a grife Richard Rogers ${ }^{1}$
}

\author{
Camilla Ramos Cardoso Bandeira \\ Graduanda em Arquitetura e Urbanismo pela Universidade Federal \\ do Rio Grande do Norte (UFRN), Avenida das Brancas Dunas, \\ 2016, Condomínio Vila Morena, Bloco 13, apto 302, Natal, RN \\ CEP 59064-720, (84) 3206-7916, milla_bandeira_@hotmail.com
}

\begin{abstract}
Resumo
O planejamento estratégico de cidades tem sido um dos instrumentos mais utilizados pelos agentes urbanos. A cidade, analisada sob a perspectiva de uma mercadoria a ser "vendida", apoia-se nas estratégias do city marketing como forma de valorizar as potencialidades que promove. Nesse contexto, a arquitetura de grife atua como catalisadora na formação de imagens representativas para a promoção da cidade e está, ainda, associada às rendas de monopólio, por meio da majoração destas, dado o seu caráter singular. Assim, cada localidade busca reunir obras de arquitetos pertencentes ao star system, como é o caso da arquitetura high-tech de Richard Rogers.
\end{abstract}

Palavras-chave: planejamento estratégico, arquitetura de grife, city marketing.

${ }^{1}$ Agradeço ao prof. Dr. Márcio Moraes Valença pelas orientações, sugestões e críticas. globalização da economia repercute hoje, para as cidades, promovendo uma espécie de mercantilização do espaço urbano. As mudanças nos perfis econômicos e produtivos, fruto da revolução tecnológica e das novas configurações territoriais, acarretaram numa disputa entre as cidades, principalmente aquelas inseridas no modelo de planejamento estratégico, por paisagens urbanas que se associem ao ideal de avanço econômico, político e social. Nessa lógica, a arquitetura espetacularizada, recheada de valoração simbólica, tem sido um dos instrumentos mais utilizados para a promoção publicitária de cidades, por meio do marketing urbano. Além do mais, esse tipo de arquitetura serve de suporte físico e imagético para fomentação do turismo cultural e na promoção de megaeventos de cunho esportivo, cultural e de lazer.

A arquitetura high-tech de Richard Rogers serve como um dos sustentáculos na construção de cidades inseridas nesse modelo. Além de ser um arquiteto de renome, prestigiado no universo das marcas, ele apresenta uma relativa preocupação com a sustentabilidade, temática bastante em voga na atualidade. É nesse contexto que percebe-se uma associação clara entre a arquitetura de grife - mais especificamente a de Richard Rogers - e a renda da terra, por meio da valoração da mesma, dado o seu caráter exclusivo.

Visto isso, este artigo propõe uma discussão sobre alguns conceitos do planejamento estratégico, bem como sua aplicabilidade, tendo em vista a importância da arquitetura de Richard Rogers como elemento constituinte desse cenário. Dessa forma, a primeira parte do texto abrange uma discussão teóricoconceitual do planejamento estratégico de cidades, "permeando" o leitor nas discussões de críticos da arquitetura e do espaço urbano como Pedro Arantes (2008), Carlos Vainer (2000) e Fernanda Sánchez (2004). Em seguida, será posta em ênfase a arquitetura de grife inserida nesse panorama, fomentando uma reflexão para tentar compreender de que maneira a produção arquitetônica de grife 
repercute na cidade. E, por fim, será abordada a obra de Richard Rogers, focando nos projetos do Centre Georges Pompidou e do Terminal 4 do aeroporto Madrid Barajas, como elementos midiáticos para uma cidade e como geradores de rendas de monopólio.

\section{Planejamento estratégico nas cidades}

Ao final dos anos 1960, os princípios de competitividade e de produtividade passaram a permear a noção de gestão das cidades, antes parte apenas da gestão empresarial. A nova forma de gestão urbana tem sido feita sob a lógica da cidade como uma mercadoria a ser agregada ao sistema financeiro global (SÁNCHEZ et al., 2004).

Vale salientar que o planejamento urbano, agora estratégico, segue um modelo das cidades que tiveram experiências bem-sucedidas e conseguiram se inserir no mercado global, com o apoio das instituições públicas locais. Em contrapartida, a implementação desses projetos é feita de maneira pontual, ou seja, criam-se nichos desenvolvidos dentro do tecido urbano, em áreas onde há o interesse de crescimento do capital imobiliário. Sánchez analisa como esses modelos de sucesso servem de base para a política local de planejamento estratégico das cidades:

Reconhecidos e tomados como modelos que devem ser seguidos tendo em vista o pretenso sucesso quando de sua aplicação em outras cidades de contextos fortemente distintos, tais enunciados têm se espraiado mundo afora, configurando o receituário a ser seguido pelas diversas localidades, em detrimento de suas respectivas identidades e/ou singularidades sociogeográficas e culturais (SÁNCHEZ et al., 2004, p. 41).

Na verdade, a adoção de modelos de gerenciamento urbano visa à promoção das cidades, com o intuito de atrair novos fluxos de capitais e de ingressar na economia global. Todavia, esse tipo de promoção não considera as diferenciações ambientais, específicas de cada região. Arantes, consoante com as ideias de Harvey, explica ainda que

[...] não apenas a arquitetura, mas todo o campo cultural privilegia as rendas monopolistas. As mercadorias culturais possuiriam uma dinâmica diferenciada em relação às mercadorias convencionais, pois sua linguagem de excepcionalidade, originalidade, autenticidade é decisiva para o estabelecimento das rendas. (ARANTES, 2008, p.177).

Pode-se se dizer que, em certa medida, a cultura, como produto mercadológico, potencializa o estabelecimento de rendas de monopólio. Sendo assim, estabelece-se um contrassenso quando o planejamento estratégico reproduz modelos prontos, que foram bem sucedidos em dada realidade, mas que não têm garantias de que serão efetivos em outras circunstâncias.

Outra questão a ser destacada reside no fato de os investimentos serem deslocados para pontos específicos das cidades, nos quais o potencial de extrair renda é mais elevado, tendo em vista determinadas condições pré-existentes, frutos de fatores como a localização e o acesso. Nesse contexto, Arantes (2008) esclarece que a arquitetura segue uma tendência de buscar muito mais as rendas, em detrimento dos lucros, em face do referido processo. A razão para tal está no fato de a arquitetura exclusiva apresentar alto custo de produção e fixidez. Ao implantar-se uma arquitetura de grife num ponto específico da cidade, todo o seu entorno será valorizado, ou seja, aumenta a renda da terra (ARANTES, 2008).

Esse processo funciona como atrativo para investimentos variados ou permite que se cobre mais por produto, mercadoria e serviços vendidos por estabelecimentos já existentes. Por exemplo, pode repercutir na elevação do preço do cardápio de determinado restaurante, no aumento do preço dos aluguéis, numa cobrança mais alta na tarifa de passeios turísticos, dentre outros.

Isso é consequência da seletividade do capital, a qual prioriza determinadas áreas criando nichos de desenvolvimento dentro da cidade, que servem como veículos de promoção. A pobreza, nessa concepção da cidade como um produto a ser vendido, é entendida como obstáculo que interfere negativamente na paisagem construída (VAINER, 2000).

Para que esses modelos tenham êxito, é necessário investir em setores rentáveis da economia, buscando 
variedade, capacidade de inovação e qualidade como critérios básicos da competitividade entre as cidades (COMPANS, 1999). Essas propostas estão em consonância com os critérios estabelecidos pela fase de financeirização da economia, fase em que o capital financeiro dinamiza a economia e o avanço das telecomunicações permite uma maior relação entre centros financeiros. Nova York, Barcelona, Paris, Bilbao e Dubai são exemplos do quanto as estratégias de marketing urbano têm sido eficientes na promoção da imagem desses locais.

Utilizadas com vistas à venda de uma imagem positiva da cidade, apoiada em infraestrutura, serviços e mão-de-obra qualificada, a fim de promovêla em escala global e atrair investimentos, as estratégias de marketing urbano têm sido a forma mais eficiente de criar uma imagem de cidade justa, segura e democrática. Nesse contexto, o empreendedorismo urbano incorpora estratégias administrativas empresariais, alterando a ordem de funcionamento da política de Estado em prol dos interesses privados (VAINER, 2000).

Assim, as parcerias público-privadas passam a viabilizar projetos, já que o setor público, sozinho, não tem condições de promover os atributos necessários ao estabelecimento de uma cidade nos moldes do city marketing (SÁNCHEZ, 2004). As transformações no âmbito da política e das instituições são fatores contribuintes para a atração de fluxos de capitais, pois geram meios para melhor "vender a cidade", impulsionados pela flexibilização econômica. Vainer (2000) explicita ainda a lógica da cidade como empresa:

[...] ver a cidade como empresa significa, essencialmente concebê-la e instaurá-la como agente econômico que atua no contexto de um mercado e que encontra neste mercado a regra e o modelo do planejamento e execução de suas funções. (VAINER, 2000, p. 86).

Todavia, vale salientar que esse mercado é restrito, uma vez que "[...] a cidade não é apenas uma mercadoria, mas também, e sobretudo, uma mercadoria de luxo, destinada a um grupo de elite de potenciais compradores" (VAINER, 2000, p. 83); ou melhor, o planejamento urbano visa atrair um público-alvo distinto. Nessa perspectiva, KaraJosé (2007, p.21) argumenta que “[...] forjar uma imagem distintiva e criar uma atmosfera de lugar e de tradição que aja como um atrativo tanto para o capital como para as pessoas do tipo certo", implica um processo de mercantilização da cultura a partir do momento em que esta passa a ser comandada pelo capital.

É o caso de Barcelona, que adotou estratégias de reestruturação urbana, investindo em infraestrutura, redes hoteleiras, sistemas viários, calçadões e restaurações, como meta de inserção no mercado de cidades. Atrelada a isso, há a promoção publicitária como forma de potencializar a imagem desta cidade: nas palavras de Arantes (2000, p. 54), há de se “[... desenvolver uma imagem forte e positiva da cidade, explorando ao máximo o seu capital simbólico".

Nesse sentido, a cidade com seu valor material busca, também, valor simbólico. A construção imagética de cidade cultural, desenvolvida, avançada e a legitimação de estratégias discursivas nas quais é necessário infundir um valor simbólico e de representação aos lugares, além do valor material, funcionam como diferencial no rol competitivo das cidades (ARANTES, 2000).

Davis (2008), por exemplo, afirma que Dubai é o protótipo da nova cidade pós-global, caracterizada por criar "apetites", mais do que por resolver problemas. Logo, as novas estratégias de negócios são direcionadas para investimentos em setores rentáveis, como o de turismo, eventos culturais e esportivos. O marketing urbano é utilizado para atrair um consumidor específico e qualificado. Em consequência, por meio desse processo de construção da cidade, há uma crescente acentuação das desigualdades sociais, chamada por Arantes (2000) de "estratégia autodestrutiva". Isso se dá pelo favorecimento de zonas de interesse, em detrimento a outras áreas menos favorecidas, repercutindo num processo pelo qual os ricos ficam mais ricos e os pobres ficam mais pobres.

Nesse panorama, a arquitetura do espetáculo é mais um veículo responsável por aumentar a atratividade das cidades. De acordo com Arantes (2008, p. 175), "[...] a sofisticação técnica ostensiva, a diferenciação das superfícies e a exuberância formal passaram a ser requisitos para constituir imagens arquitetônicas exclusivas, capazes de valorizar os investimentos e, consequentemente, as cidades que os disputam". 
Um exemplo disso é o Museu Guggenheim, em Bilbao, Espanha. Antes de o museu ser construído, a cidade estava passando por uma crescente desindustrialização e estagnação econômica. Graças ao projeto de Frank Gehry, a cidade basca passou a ser conhecida por todo o mundo, o que acabou por gerar rendas de monopólio para investidores nesse modelo de gestão, por meio da construção de hotéis, restaurantes e espaços de lazer (ARANTES, 2008). As vantagens usufruídas pela detenção do solo repercutem em certas vantagens relacionadas com a localidade, o acesso e a exclusividade; permitem extrair maiores benefícios do que aqueles localizados em outras regiões.

A união das marcas Gehry, Guggenheim e Bilbao foi um forte instrumento de divulgação publicitária, ocasionando uma circulação de capital bem maior na região. Assim, a criação de espaços públicos e edificações associados a arquitetos do star-system propicia a construção de imagens da cidade, visando o turismo cultural (Figura 1). Acerca da relevância do Guggenheim em Bilbao como referência de planejamento estratégico, Bonates (2009) destaca que

Figura 1: Entorno do Museu Guggenheim, Bilbao. Fonte: Imagem cedida por Márcio Valença, 2008
[...] embora a arquitetura de grife, de modo geral, seja caracterizada como indiferente ao lugar, o que se verifica são várias inter-relações com o espaço urbano existente, mesmo que sejam apenas medidas para valorizar mais ainda o edifício, sem falar da localização privilegiada em frente à Universitat de Deusto. (BONATES, 2009).

Essa estratégia de investimento na imagem e na simbologia da cidade serve para produzir um valor agregado a Bilbao. Além de Bilbao, outras cidades investem na arquitetura, produzindo uma imagem de marca como forma de produzir valor agregado. A percepção do consumidor (observador) sobre determinado produto ou serviço varia de acordo com a capacidade de se produzir um valor tangível imensurável sobre determinado produto. A associação da grife do arquiteto com a arquitetura do espetáculo produz um valor diferencial na percepção do consumidor (observador), adicionando um valor a mais, ou seja, um valor agregado.

Assim, ao notar o enorme potencial que a arquitetura contemporânea apresenta em gerar rendas para uma cidade, os capitalistas, gestores urbanos e demais agentes passaram, a partir de parcerias público-privadas, a procurar criar lugares exclusivos com uma arquitetura de ponta (ARANTES, 2008).

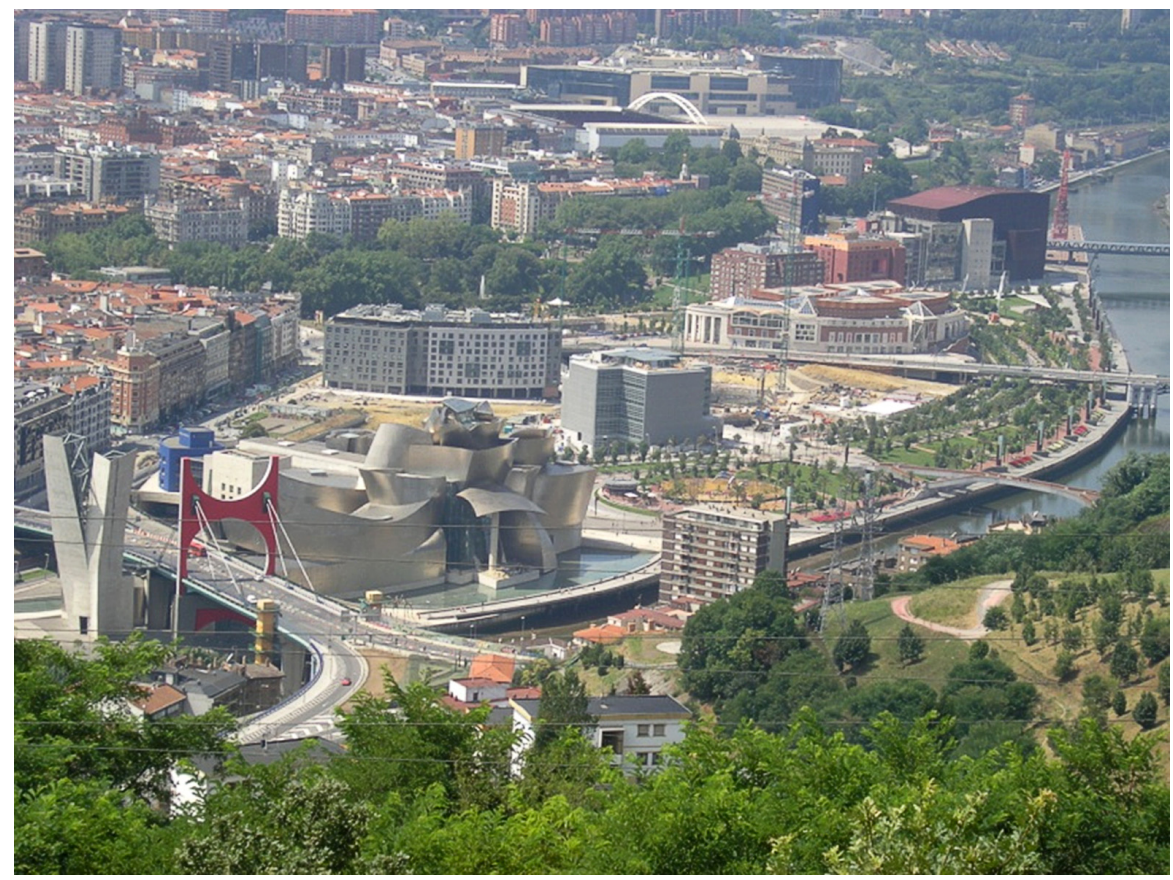


Arantes (2000) defende ainda que as cidades buscam tornar-se atraentes para o capital estrangeiro, inclusive no setor imobiliário. Quanto menos restrições, mais atratividade terá. Isso se torna evidente ao se verificar a arquitetura midiática, objetivo perseguido pelos diversos centros financeiros. Em consonância com esse pensamento, Arantes (2008) reforça a ideia de que quanto menos regras, maior é a liberdade inventiva sobre determinada obra, maior é seu caráter exclusivo, maior é sua proporção, maior é seu sucesso de público, maior é seu poder de atração e maiores serão suas rendas. Sobre isso, Sánchez argumenta que:

É necessário ressaltar, entretanto, que o aumento da atratividade da cidade, objetivo perseguido pela imagem de 'renascimento urbano' sobre os mercados exteriores, atua, sobretudo, com a idéia de qualidade de vida, reforçada pela imagem de consenso social que proporciona a legitimação do projeto hegemônico para a população em geral. (SÁNCHEZ, 2004, p. 129).

O consenso em torno de um projeto é fundamental na unificação da cidade, e isso só se constrói com uma "consciência de crise" seguida de patriotismo cívico, como parte do projeto ideológico (VAINER, 2000). Atrelados ao processo de construção ideológica, em torno de um projeto de renovação urbana realizada com êxito, encontram-se os meios de comunicação e informação. Esses instrumentos são capazes de construir valores culturais e valores de representações sociais, tendo a capacidade de influenciar a nossa concepção de cidade e de uso dos espaços públicos.

É válido ressaltar também como as forças dominantes, por meio dos seus discursos, usam de artifícios para envolver todos os cidadãos nos projetos de cidade. Isso porque o sentimento de orgulho e a participação ativa anulam o senso crítico de uma parte da população, pois, mesmo que tais projetos excluam a participação direta das classes menos favorecidas, a ideologia infundida gera um consenso favorável a eles (VAINER, 2000).

Lima (2004) discute as transformações do espaço urbano, como estratégias mais econômicas do que sociais, dentro dos novos programas de renovação urbana.
Estas obras inusitadas de arquitetura atuam como vitrines publicitárias da cidade-espetáculo, tentando despertar o orgulho dos cidadãos e pretendendo neutralizar os muitos conflitos sociais. Não há sempre ingenuidade nos projetos espetaculares de arquitetura. Eles servem quase sempre para esconder outras regióes da cidade onde reina a pobreza, a falta de educação e a miséria. (LIMA, 2004, p. 2).

Essa tendência de se constituir lugares modernos e inovadores, com repercussão no meio publicitário sem, portanto, haver preocupação em estabelecer um elo com a história do lugar e dos habitantes ali residentes, provoca mudanças no tecido urbano, em função de interesses mais particulares que coletivos. Dubai, nos Emirados Árabes, mesmo fortemente atingida pela crise financeira internacional pós2008, é um exemplo da gestão urbana flexível para os investidores. Essa "ilha utópica" é isenta de impostos, não apresenta partidos oposicionistas e não tem sindicatos. Conforme Davis (2007, 46-47) "Dubai se converteu no novo ícone do urbanismo criativo", ou seja, por intermédio da arquitetura pós-moderna (exclusiva, inovadora, inusitada etc.), das imagens midiáticas e do marketing urbano, os investimentos aplicados buscam suprir as vontades e os desejos de uma elite mundial com um elevado poder de compra.

Os atores públicos e privados, dentro desse processo, se direcionam cada vez mais a realizar transformações no tecido urbano, voltadas para uma elite de investidores e compradores. A promoção de uma imagem positiva do desenvolvimento local, a propaganda midiática e a realização de projetos em grande escala assinados por arquitetos de grife são soluções efetivas na consolidação da gestão excludente das cidades que usam do sentimento de pertencimento para promover as obras realizadas.

Por outro lado, enquanto o planejamento estratégico está focado em atender às necessidades de um público-alvo específico - vale salientar que isso não é posto de modo explícito aos cidadãos também a marginalização, a pobreza, as favelas e a desigualdade social têm marcado as paisagens de muitas cidades contemporâneas.

Pode-se dizer, em linhas gerais, que a arquitetura de grife tende a favorecer o processo de acentuação 
das desigualdades sociais nas cidades, a partir do momento em que se volta para uma classe distinta da sociedade. Por outro lado, dada sua imagem representativa, a arquitetura de grife vem ganhando papel de destaque nas intervenções urbanas, consolidando o modelo de planejamento estratégico de cidades.

\section{A arquitetura de grife e sua repercussão na cidade}

As mudanças das concepções da arquitetura, entre o século $X X$ e o século $X X I$, resultaram nesse jogo de representatividade-atratividade. No modernismo - com destaque entre o período dos anos 1910 aos 1950 -, inspirado pelo maquinismo e pelo racionalismo, os projetos eram feitos de maneira técnica e formal com pouca ornamentação e poucos ângulos retos. O capital industrial movia a economia da época e criou-se a necessidade de se produzir uma arquitetura mais voltada à questão estrutural e funcional dos ambientes. Já no século XXI, a arquitetura é movida pelo capital financeiro; logo, a imagem passa a ser mais importante do que a estrutura em si (ARANTES, 2008). Isso porque os novos equipamentos tecnológicos darão suporte à logística de circulação do capital, a partir do momento que a tecnologia permite reduzir as fronteiras entre as global cities, com a construção de edifícios inteligentes, sistema de telecomunicações eficiente, com equipamentos avançados. Seguindo essa lógica, os capitalistas passam a intervir nos espaços urbanos, criando imagens arquitetônicas inovadoras, nas quais a tecnologia, a imagem e a representação são mais valorizadas que as estruturas em si. O objetivo dos agentes urbanos é fazer uma arquitetura exclusiva. Ou seja, quanto mais diferenciadas forem as formas, os materiais utilizados, os efeitos construtivos, a tecnologia aplicada à arquitetura, mais chamativa será a obra, aumentando seu sucesso de público e, por consequência, valorizando a obra em si e a cidade que a possui. Dessa maneira, a obra singular possibilitará certa renda de monopólio (ARANTES, 2008).

$\mathrm{Na}$ atualidade, observa-se uma busca pela espetacularização arquitetônica. Vale ressaltar que essa arquitetura esteve sempre ligada aos setores mais influentes, em termos econômicos e políticos de uma sociedade. A diferença entre marcos arquitetônicos de civilizações antigas e modernas reside na propositalidade em se produzir esse tipo de arquitetura. Enquanto, anteriormente, esse tipo de arquitetura refletia o poder de uma civilização, hoje tal produção é enrustida de valoração capitalista, no sentido de se produzir um valor imensurável à obra e promover um caráter sólido às instituições e às grandes empresas que financiam esse tipo de investimento. Como consequência, essas empresas usam da publicidade para fortalecer suas imagens e usufruir de um novo tipo de renda, aquela que advém do valor simbólico (ARANTES, 2008).

A construção de simbologias sobre determinado produto materializado produz um valor superior ao que realmente ele representa. A mais-valia dessas empresas se dá pela construção de imagens representativas do material em si como produto simbólico (ARANTES, 2008), ou seja, agrega-se valor "humano" aos objetos, descaracterizando-os de sua forma mais primitiva. Para que haja um melhor entendimento, pensemos numa Ferrari, ou numa Mercedes, ou numa BMW. Quem a compra, não compra apenas um veículo, mas a grande marca. E, apoiado nessa marca, com a qual se infunde significado aos objetos, "compra-se" também status, poder e modernidade.

Conforme essa lógica, as instituições perceberam que fortificar uma imagem de marca arquitetônica geraria mais lucro, da mesma forma como acontecia com os produtos materiais. Nessa perspectiva, cada cidade procura construir uma imagem forte, apoiada em obras de arquitetos reconhecidos internacionalmente. Um exemplo recorrente e em destaque é Dubai, localizada nos Emirados Árabes. Essa cidade está investindo demasiadamente na produção da marca Dubai. Ao proferir a própria palavra "Dubai", o que vem à mente são os grandes arranha-céus, a arquitetura exclusiva e monumental - assinada por arquitetos de grife. Além disso, Dubai transmite a imagem de um grande centro de lazer e de compras. E, afim de lucros, é justamente a produção dessa simbologia de cidade moderna, avançada, onde há grandes centros de consumo e lazer, que possibilita a venda dessa cidade e dessa marca para os consumidores solváveis e de grande potencial de compra.

Como revela Davis, sobre a transformação de Dubai em uma cidade "fantasmagórica": 
Dubai está construyendo el parque temático más grande Del mundo, el mayor centro comercial y de ocio (y, em su interior, el mayor acuario), el edifício más alto, el mayor aeropuerto internacional, la isla artificial de mayor extensión, el primer hotel sumergido [...] Desde el punto de vista de su importância en el desarrollo de Dubai, la caricatura monstruosa del futurismo no es más que um astuto modo de crear uma marca para el mercado mundial. (Davis, 2008, p. 47-48).

Um aspecto a ser observado é que, nos grandes booms de modernização das cidades, a arquitetura faraônica, imponente em relação ao design e à escala, sempre se faz presente. Um exemplo foi o Empire State Building, em Nova York, construído em 1931 e considerado o maior edifício do mundo por vários anos. Outro exemplo, mais recente, é o Hotel Burj Al Arab, em Dubai, que, além se ser o hotel mais alto do mundo, também está associado a essa questão da transição de uma renda baseada no petróleo para novas formas de se extrair renda, nesse rápido investimento em modernização (DAVIS, 2007).

Por conseguinte, percebe-se que os agentes urbanos visam construir, na cidade, uma arquitetura monumentalista, agregando-Ihe valor simbólico, tendo em vista a necessidade de extrair rendas monopolistas. O controle sobre a forma e a imagem é elemento decisivo na constituição de determinada simbologia sobre determinados "objetos", que, apoiados por arquitetos de grife e pelo marketing de cidades, são transformados em imagens publicitárias a serem "vendidas" (ARANTES, 2008).

A constituição da arquitetura high-tech nas cidades, utilizando a tecnologia a favor dos projetos arquitetônicos, serve de base para formular imagens positivas do desenvolvimento do local no qual estão implantadas. A exemplo da arquitetura de Richard Rogers, consagrado arquiteto no panorama da produção internacional, verifica-se que essa produção imagética tem um efeito sinérgico nas pessoas, que passam a analisar a obra de um caráter material a um imaterial, anulando, de certa forma, o conteúdo crítico daquela forma de representação. Será, portanto, a combinação da arquitetura hightech + arquiteto de grife + publicidade + lazer a "fórmula mágica" para o sucesso econômico de uma cidade?

\section{Richard Rogers: uma grife high-tech e sustentável}

Considerando a arquitetura de grife como uma componente do planejamento estratégico de cidades e constatando a sua importância na formação da imagem da cidade, iremos agora considerar o trabalho do arquiteto Richard Rogers, reconhecido internacionalmente por sua arquitetura high-tech. Em suas obras, Rogers utiliza a tecnologia em favor de seus projetos, tendo em vista o anseio de se produzir uma arquitetura inovadora e, ao mesmo tempo, seguir consoante os princípios de eficiência energética.

Para Rogers, as cidades estão se transformando continuamente. Nos últimos anos, as alterações climáticas passaram a impor novas necessidades às práticas produtivas e industriais a fim de melhorar a qualidade de vida nas cidades. Nesse contexto, há uma tendência da arquitetura de grife em buscar construir locais, além de funcionais e esteticamente diferenciados, ecologicamente corretos. Dessa forma, a "cidade mercadoria" incorpora também a imagem de cidade sustentável, preocupada com o bem-estar e a sustentabilidade do planeta.

Essa relação entre a cidade como mercadoria e a cidade sustentável, tendo em vista a construção de edifícios utilizando fontes renováveis de energia - vento, sol e água -, consolida a promoção de uma imagem positiva da cidade. Isso porque a temática ambiental está em bastante evidência nos meios de comunicação de massa e nas discussões das autoridades globais. Nessa lógica, a preocupação em planejar uma cidade ecologicamente correta, visando à qualidade de vida dos moradores, com uma arquitetura de ponta que combine design e sustentabilidade, fortalece o status da cidade e constitui um diferencial no rol de cidades competitivas

Rogers acredita que o desenvolvimento urbano sustentável depende de três fatores: qualidade da arquitetura, bem-estar social e responsabilidade ambiental (ROGERS, 2009). O primeiro fator refere-se à preocupação em produzir uma arquitetura além de sua aparência estética. Ou seja, a arquitetura de qualidade estaria também representada nos espaços internos, nas conexões das partes, formando um todo harmonioso e funcional com a paisagem. O segundo fator corresponderia a um edifício que dialogasse com o indivíduo, levando em consideração a adequação 
da edificação no lugar. E, por fim, a responsabilidade ambiental traduz-se pela utilização de tecnologia de ponta aplicada nos elementos construtivos para dar suporte à construção de edifícios inteligentes.

Esses três domínios são encarados pela equipe do escritório Richard Rogers Partneship (RRP), que busca realizar obras onde haja equilíbrio entre domínio público e privado, empregando sistemas avançados quanto à redução do consumo energético e utilização de fontes renováveis, visando estabelecer uma relação harmoniosa entre a cidade construída e os habitantes que nela habitam. A união dessas partes resultaria em uma cidade social e ecologicamente responsável, potencializando a atratividade de visitantes e investidores.

Com relação à qualidade da arquitetura, esta não se restringe apenas a projetos ecologicamente corretos e únicos, mas leva em conta também a flexibilidade desses espaços. Realizar uma arquitetura flexível que perdure às mudanças temporais, possibilitando uma "vida durável" mais longa ao edifício, assim como propor soluções espaciais a curto e longo prazos são características da arquitetura de Rogers. Para ele, velocidade, eficiência energética e custo imprimem soluções formais de leveza, transparência e clareza do desenho (ROGERS, 2009).

2 As imagens dos casos que serão analisados aqui podem ser facilmente encontradas na internet.
De acordo o próprio site de Rogers (2009), atualmente seu escritório compõe uma equipe de aproximadamente em média cento e quarenta pessoas, incluindo quarenta associados e dez membros. A sede principal do escritório localizase em Londres, com mais três sedes em Madrid, Barcelona e Tóquio. Seu repertório agrega um extenso acervo com mais de quarenta e oito obras concluídas, estando a maioria delas localizada em Londres, e as demais em Taiwan, Coréia, Estados Unidos, Itália, Espanha e França.

Por essas singularidades, Rogers é um arquiteto reconhecido internacionalmente, cujo trabalho já obteve diversas premiações. Em 1985, Rogers foi homenageado com a Royal Gold Medal para Arquitetura, pelo Instituto de Arquitetos Britânicos. Recebeu o prêmio Stirling, pelo Terminal 4 do Aeroporto de Barajas, Madrid. Foi homenageado com o prêmio Praemium Imperiale pela Japan Art Association, em 2000. Em 2007, recebeu o prêmio Pritzker de Arquitetura, que é considerado o “Oscar da
Arquitetura", fortalecendo o caráter representativo de sua arquitetura high-tech e tornando-o uma referência de arquiteto no panorama internacional.

Em consequência, constroem-se representações da marca Rogers, apoiadas na divulgação publicitária, a fim de promover a marca. A construção de frases de efeito, como "Richard Rogers, o humanista tecnológico" ou "Richard Rogers, o arquiteto que ajudou a transformar Londres", contribui para o fortalecimento do próprio arquiteto, de seus projetos, como também das cidades em que estes são executados. Nesse sentido, de acordo com Arantes (2008), a arquitetura de grife (Rogers é um entre tantos exemplos), experimenta uma fusão entre publicidade e entretenimento tendo em seus projetos a base da consolidação de sua arquitetura única, com rebatimento na promoção local da cidade, visando potencializar os negócios e, em particular, o turismo.

Richard Rogers possui um diversificado acervo de obras, e essas representações arquitetônicas marcaram fases específicas de sua carreira. Considerando que o objetivo deste estudo é entender como a arquitetura de grife se insere no planejamento de cidades, como um veículo de promoção destas, aqui serão analisadas duas obras ícones do arquiteto, que incorporam características essenciais da arquitetura high-tech ${ }^{2}$.

\section{A arquitetura high-tech de Rogers}

O Centro Nacional de Arte e Cultura Georges Pompidou (Figura 2), ou simplesmente, Pompidou, inaugurado em 1977, foi fruto da associação entre Richard Rogers e Renzo Piano. Após participar do concurso para realização do projeto, cujos requisitos eram a livre circulação e a abertura da exposição para espaços e funções variadas, como salas de música, filmes, atividades de expressão, a associação Rogers-Piano desenvolveu um projeto atípico, mas vencedor do concurso. A ideia era criar um centro cultural e de lazer que pudesse atender às diversas classes sociais, sendo utilizado como um espaço de convivência. Para isso, configurou-se uma praça central que serviria como espaço público, no qual as atividades externas se estenderiam para a parte interna da edificação.

Inspirados pelo movimento high-tech dos anos 1960, o Pompidou foi a primeira experiência dessa 


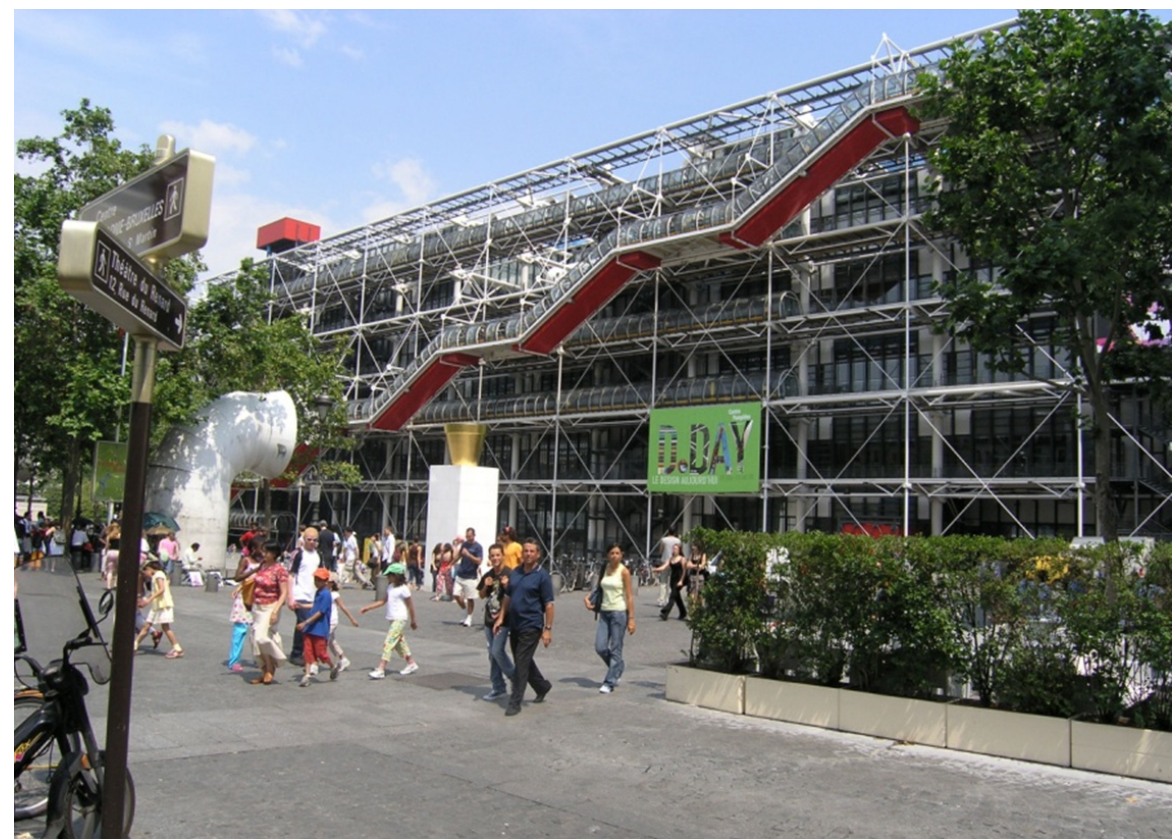

Figura 2: Centro Pompidou, Paris. Fonte: Imagem cedida por Márcio Valença, 2005. tendência arquitetônica. O objetivo era fazer um projeto flexível que pudesse se adequar, ao longo dos anos, a ampliações futuras; que possibilitasse variações na divisão dos espaços internos e que primasse pela circulação. Com isso, a proposta foi deslocar as estruturas e os serviços para o exterior, proporcionando a flexibilidade interna desejada, além de esses atributos servirem como o próprio design da edificação. As partes de circulação e acesso são feitas por meio de elevadores e escadas rolantes, também localizadas na parte exterior da edificação, permitindo aos visitantes desfrutarem das vistas dos telhados antigos de Paris e da própria estrutura inusitada da edificação (ROGERS, 2009).

Pelo seu caráter "transgressor", já que não havia, até o momento, um projeto dessa magnitude que fizesse uso da estrutura aparente, o Centro Pompidou foi alvo de diversas críticas. Todavia, a aceitação do público foi positiva, fortalecendo o caráter representativo que essa nova tendência de arquitetura imprimia como instrumento revitalizador de uma área urbana.

Por ser um dos principais exemplos de arquitetura high-tech, o Pompidou foi considerado um edifícioâncora do bairro do Marais, em Paris. Essa região, localizada no centro da cidade, encontrava-se num processo de estagnação. As estratégias de revitalização desses centros como forma de tornar a área novamente atrativa, disponibilizando serviços como restaurantes, lojas e grandes operações de intervenção - com a implantação de centros culturais de grande porte -, serviram de base para o projeto de intervenção no bairro.

Nesse contexto, o Centro Pompidou atuou como catalisador daquela região, tendo em vista a dinamização da área, por meio da atração de serviços voltados para o consumo. Vale salientar que esse modelo intervencionista resultou em fenômenos de gentrificação, na medida em que houve o enobrecimento da área (CLERVAL, 2006). Como consequência desse fenômeno, observamse o deslocamento da população de baixa renda - sem condições de se manter no local, em razão do aumento do aluguel e das taxas dos serviços, além da descaracterização cultural da região - e a atração de moradores de classe média para essas regiões.

As estratégias de renovação urbana se apoiam nos equipamentos culturais de grande porte e usam da construção de uma simbologia por meio da grife do arquiteto, no caso da associação entre Richard Rogers e Renzo Piano, e da própria arquitetura como 
equipamento de divulgação midiática, para revitalizar uma área antes degradada, transformando-a em um centro dinâmico (ARANTES, 2000). Essa estratégia gera rendas de monopólio para a cidade (ARANTES, 2008). O investimento no Pompidou que, de acordo com o site do arquiteto, atrai cerca de sete milhões de visitantes por ano, é um canal eficiente de divulgação midiática da cidade de Paris. Após trinta anos de concluído, o Pompidou continua sendo um os edifícios mais visitados na França. A grande praça localizada no site cumpre seu papel de espaço público promotor de uma dinamicidade local, tendo como respaldo a cultura. Como efeito, o turismo cultural contribui para a dinamização da economia, movimentando capital e atraindo outros tipos de investimentos como hotéis, aeroportos, restaurantes e também outros projetos de grife.

De forma geral, o Pompidou é um marco tanto para Paris como para a arquitetura, tendo em vista seu papel como edifício-âncora para uma área antes estagnada e "sem vida" da capital, viabilizado por meio de um projeto que transgredia as concepções arquitetônicas da época, caracterizando uma arquitetura de exceção para a cidade.

\section{A flexibilidade arquitetônica}

A tendência em se construir obras de arquitetos renomados e projetos de grande visibilidade dentro da cidade, tendo em vista o interesse de inserção no mercado global, segue o modelo de planejamento estratégico de cidades. Sob essa perspectiva, as construções de grandes aeroportos, associadas aos arquitetos do star-system, acompanha as estratégias de promoção publicitária e simbólica. No entanto, como esse tipo de investimento necessita de vultosa quantia de capital, são poucas as cidades capazes de direcionar tamanha verba para uma obra dessa magnitude. Por essa razão, esse tipo de associação - arquitetura exclusiva + arquiteto de grife - é mais evidente nas cidades globais e/ou nas quais prevalece o city marketing.

Cidades como Hong Kong, Barcelona e Bilbao possuem aeroportos assinados por Norman Foster, Ricardo Bofill e Santiago Calatrava, respectivamente. Madrid não foge à regra. O projeto para o novo Terminal 4 do aeroporto Madrid Barajas teve como arquiteto Richard Rogers em parceria com o Estúdio Lamela. O projeto foi feito de maneira a tornar Madrid um importante hub europeu, consolidando-a como ponto de entrada e saída entre a Europa e a América Latina. Para isso, a edificação se estende por uma área de aproximadamente um milhão de metros quadrados, tendo capacidade para receber, em média, 35 milhões de pessoas anualmente (ROGERS, 2009).

Como característica marcante da arquitetura de Rogers, a flexibilidade, a sustentabilidade e a preocupação em projetar de forma que o ambiente urbano se integre ao social foram quesitos fundamentais para a concepção arquitetônica e estrutural do Terminal 4. As extensas fachadas de vidro permitem aos passageiros e visitantes aproveitarem as vistas para as montanhas e para as aeronaves. As formas onduladas da cobertura aproximam-se das formas naturais da paisagem externa e horizontal, de Madrid. O projeto apresenta uma clara progressão linear dos espaços para facilitar o fluxo de chegada e saída de passageiros e contribuir na usabilidade do terminal. Essa conformação linear possibilita, por exemplo, intervenções futuras para a ampliação do terminal (ROGERS, 2009).

Em termos de sustentabilidade, o projeto atende ao compromisso do fazer ecologicamente correto. As aberturas que acompanham a linearidade da edificação permitem a entrada da luz do sol, maximizando a luz natural incidente ao longo dos corredores. Foi também desenvolvido um sistema de coleta de água da chuva com a finalidade de irrigar as zonas verdes e a cobertura do estacionamento, objetivando diminuir o calor retido em suas superfícies. Dessa forma, o Aeroporto Madrid Barajas se destaca, em relação a projetos da mesma linha, por ser adaptável a alterações futuras, unindo a estética à funcionalidade, de maneira eficaz, e por reduzir custos com manutenção, por meio da utilização de fontes renováveis de energia.

Por explorar novas formas arquitetônicas, de materiais e por ser um projeto sustentável, a obra de Rogers agrega valor simbólico. Isso ocorre por meio da associação de arquitetos de grife e o marketing de cidades, o qual transforma a obra em imagem publicitária a ser mostrada como uma "vitrine" da cidade. No caso do Barajas, o projeto foi concebido para ajudar a tornar Madrid um importante hub europeu. A visibilidade alcançada em razão da construção do aeroporto é de grande magnitude, repercutindo de forma positiva para a cidade. 


\section{Conclusão}

A utilização do objeto arquitetônico, na lógica de mercado globalizado, transcende a essência da matéria tectônica e representa em si o poder simbólico das grandes corporações e instituições que visam investir em sua imagem, por meio de arquiteturas espetaculares. Dado o investimento em novas tecnologias e a vasta expansão das telecomunicações, essas empresas e cidades apoiamse na divulgação midiática para expandir seus produtos para novos mercados.

Dessa maneira, uma grande arquitetura - que não se refere necessariamente à sua escala dimensional, mas ao caráter único que ela possui -, assinada por um arquiteto renomado, reconhecido globalmente, tem rebatimento na valorização da cidade. A arquitetura de Richard Rogers é um exemplo disso. Do extenso repertório de obras icônicas, os casos apresentados, o do Centro Pompidou e Terminal 4 o do Aeroporto Madrid Barajas, atestam o comprometimento do escritório em realizar uma arquitetura que apresente, além de qualidade espacial e ambiental, uma singularidade projetual (fatores determinantes no posicionamento atual de Rogers diante do cenário mundial). Como efeito, o branding arquitetônico da marca Rogers torna-se um instrumento das políticas urbanas, já que transmite imagens e representações da cidade.

É válido reconhecer a arquitetura de grife e sua instrumentalização no planejamento estratégico como um trabalho que requer habilidade técnica. Os grandes escritórios compostos por arquitetos de renome e, mais especificamente, o de Richard Rogers, que totaliza uma equipe de aproximadamente cento e quarenta pessoas, evidenciam o alto nível de complexidade dos projetos e a elevada quantidade de obras encomendadas. Os arquitetos pertencentes ao star-system possuem um aparato técnico e hábil capaz de alcançar soluções espaciais ilimitadas. Cada um busca realizar um projeto que seja totalmente diferente de tudo que já foi visto ou então que se assemelhe a objetos comuns, todavia executados em uma escala macro. A tecnologia das estruturas e dos materiais dá subsídio a essa façanha. Partindo desse ponto, a competitividade permeia também o campo das arquiteturas. Da mesma maneira que as cidades competem entre si investindo em soluções rentáveis, as arquiteturas disputam soluções exclusivas.
Cabe ressaltar que um processo está vinculado ao outro. Não há como dissociar exclusividade arquitetônica e renda da terra. Tais fatores estão conjugados pelo que Arantes (2008) considera como "renda de monopólio". Como discutido, o grau de singularidade de uma obra influencia o entorno na qual ela está implantada, tendo como efeito, inclusive, a majoração dos preços e, por conseguinte, a maximização dos lucros sobre bens e serviços. Os projetos do Centro Pompidou e do Terminal 4 do Aeroporto Madrid Barajas se enquadram nesse contexto. O Pompidou tornou-se símbolo de referência de uma linguagem puramente high-tech, inovando a concepção da produção arquitetônica em seu período histórico e simbolizando a tecnologia aparente em favor da estética do edifício. Por outro lado, a reforma do Terminal Barajas incorpora elementos construtivos sustentáveis e explora a relação do edifício em seu meio. O aeroporto de Madrid, após a reforma, tornou-se uma importante "porta de entrada" da Europa, configurando-se um dos terminais mais visitados da Europa.

Vale salientar que esses "projetos de efeito" requerem alto custo de investimento, tanto para financiar a marca do arquiteto como para produzir uma arquitetura única que se utilize de tecnologia avançada. O projeto é executado como se fosse um quebra-cabeça, onde cada parte da estrutura é composta por uma peça única. Por não haver reprodutibilidade dessas peças, a arquitetura contemporânea compõe, em sua totalidade, uma verdadeira obra de arte. Contudo, essa "obra de arte", se assim pode se dizer, é, geralmente, restrita à utilização de uma classe média e alta, com poder de consumo elevado. Muitas vezes o senso crítico de quem a utiliza é anulado, pois, por agregar valores simbólicos divulgados pela mídia em relação à arquitetura de grife, tende-se a analisar a obra considerando somente sua aparência externa em detrimento de seu conteúdo.

\section{Referências bibliográficas}

ARANTES, Otília. Uma estratégia fatal. A cultura nas novas gestões urbanas. In: ARANTES, Otília; VAINER, Carlos; MARICATO, Ermínia. (Org.). A cidade do pensamento único. Desmanchando consensos. Petrópolis, RJ: Vozes, p.11-74, 2000.

ARANTES, Pedro. O grau zero da arquitetura na era financeira. Novos Estudos. CEBRAP, n.80, p.175195, 2008. 
BONATES, Mariana Fialho. "El Guggenheim y mucho más" - Urbanismo monumental e arquitetura de grife em Bilbao. Revista do Programa de Pós-graduação em Arquitetura e Urbanismo da FAUUSP, v.16, n.26, p.62-90, dez. 2009.

CLERVAL, Anne. Gentrification, a frontier reshaping social division of urban space in the inner Paris. Disponivel em: <http://hal-paris1.archives-ouvertes.fr/halshs00152809/>. Acesso em: 23 nov. 2009.

COMPANS, Rose. O paradigma das global cities nas estratégias de desenvolvimento local. Revista Brasileira de Estudos Urbanos e Regionais, n.1, maio 1999.

CASTELIS, Manuel; BORJA Jordi. As cidades como atores políticos. Novos Estudos do Cebrap, São Paulo, n.45, p.152-166, jul. 1996.

DAVIS, Mike. Sand, fear and money in Dubai. In: Evil paradises. New York:The New Press, 2007

KARA-JOSÉ, Beatriz. Políticas culturais e negócios urbanos: a instrumentalização da cultura na revalorização do centro de São Paulo (1975-2000). São Paulo: Annablume; Fapesp, 2007.

LIMA, Evelyn Furquin Werneck. Configurações urbanas cenográficas e o fenômeno da "gentrificação". Disponível em: <http://www.vitruvius.com.br/arquitextos/ arq046/arq046 03.asp>. Acesso em: 04 mai. 2009.
ROGERS, Richard Disponível em: <http://www.richardrogers.co.uk/theory>. Acesso em: 24 abril 2009.

ROGERS, Richard. Disponível em: <http://www.richar drogers.co.uk/work/all projects/centre pompidou/completed>. Acesso em: 9 mai. 2009

ROGERS, Richard. Disponível em: <http://www. richardrogers.co.uk/work/all_projects/madrid barajas airport/completed $>$. Acesso em: 23 mai. 2009

SÁNCHEZ, Fernada; Bienenstein, Glauco et al. Produção de sentido e produção do espaço: convergências discursivas dos grandes projetos urbanos. Revista Paranaense de Desenvolvimento, Curitiba, n.107, p.39-56, jul./dez. 2004.

SÁNCHEZ, Fernanda. A reinvenção das cidades na virada de século: agentes, estratégias e escalas de ação política. Revista de Sociologia Política, Curitiba, 16, p.31-49, jun. 2001.

VAINER, Carlos. Pátria, empresa e mercadoria. Notas sobre a estratégia discursiva do planejamento estratégico urbano. In: ARANTES, Otília; VAINER, Carlos; MARICATO, Ermínia. (Org.). A cidade do pensamento único. Desmanchando consensos. Petrópolis RJ: Vozes, p.75-103, 2000. 
The monumental architecture whitin the strategic planning for cities: architecture rentier designer Richard Rogers

Camilla Ramos Cardoso Bandeira

\begin{abstract}
Strategic planning of cities has been one of the most used tools by urban agents. The city, considered from the perspective of a merchandise to be "sold", is based on the strategies of city marketing as a way to harness the potential that it promotes. In this context, brand architecture acts as a catalyst in the formation of representative images to promote the city and is also associated with monopoly rents through the increase of the latter, given its unique character. Thus, each locality has tried to bring together works of architects belonging to the star system, as is the case of Richard Rogers' high-tech architecture.
\end{abstract}

Keywords: strategic planning, brand architecture, city marketing.

\title{
La monumentalidad arquitectónica dentro del planeamiento estratégico de ciudades: la arquitectura rentista y la marca Richard Rogers
}

Camilla Ramos Cardoso Bandeira

\section{Resumen}

El planeamiento estratégico de las ciudades ha sido uno de los instrumentos más utilizados por los agentes urbanos. La ciudad, analizada bajo la perspectiva de una mercadoría que va ser "vendida", apoyándose en las estrategias del city marketing como forma de valorar las potencialidades que promueve. En este contexto, arquitectura de marca actúa como catalizadora en la formación de imágenes representativas para la promoción de la ciudad y está, todavía, asociada a las rendas de monopolio, por medio del aumento de estas, dado su carácter singular. Así, cada localidad busca reunir obras de arquitectos pertenecientes al star system, como es el caso da arquitectura high-tech de Richard Rogers.

Palabras clave: planeamiento estratégico, arquitectura de marca, city marketing. 